\title{
KAJIAN INDEKS DAYA SAING DESTINASI PARIWISATA DI KABUPATEN MANGGARAI BARAT
}

\author{
Septian Hutagalung, Moyo Hady Poernomo, Dodi Riadi, Roseven Rudiyanto \\ Politeknik eLBajo Commodus Manggarai Barat, Nusa Tenggara Timur, Indonesia \\ Email: septian.hutagalung@poltekelbajo.ac.id, moyohady@gmail.com, \\ dodiriadi@gmail.com,roseven@poltekelbajo.ac.id
}

\begin{abstract}
Abstrak
Penetapan Labuan Bajo Flores menjadi Destinasi Super Prioritas di 2019 perlu diiringi dengan pembangunan infrastruktur dan praktik manajemen pariwisata yang berkelanjutan. Dalam mencapai tujuan pembangunan ini perlu diadakan pengukuran kesiapan infrastruktur pendukung pariwisata yang nantinya akan jadi dasar rekomendasi pengembangan di destinasi Labuan Bajo Flores. Dalam penelitian ini mengadopsi indikator dalam kajian Tourism and Travel Competitiveness Index (TTCI) atau Indeks Daya Saing Destinasi Pariwisata yang dikeluarkan oleh World Economic Forum (WEF). Dengan dilakukannya kajian TTCI maka akan diperoleh pemetaan kondisi sektor pariwisata di Kabupaten Manggarai Barat dalam hal produk pariwisata, infrastruktur, regulasi pemerintah, dan sektor-sektor pendukung. Selain itu, data ini dapat menjadi dasar rekomendasi penetapan kebijakan internal, perencanaan dan pengembangan destinasi pariwisata yang berkelanjutan di Kabupaten Manggarai Barat. Pengumpulan data dilakukan melalui kuisioner TTCI dan wawancara yang dibagikan saat Focus Group Dissusion. Hasil penelitian menunjukkan performa industri pariwisata Kabupaten Manggarai Barat secara total berada pada nilai nilai 2.1 yang berarti berada pada tahap penyempurnaan. Nilai variabel pada masing-masing empat variabel utama berada pada nilai 2.2 pada variabel produk dan regulasi, kemudian untuk nilai infrastruktur dan support berada pada nilai 2.1.
\end{abstract}

Kata Kunci: labuanbajo; pariwisata; TTCI

\section{Abstract}

The determination of Labuan Bajo Flores as a Super Priority Destination in 2019 needs to be accompanied by infrastructure development and sustainable tourism management practices. In achieving this development goal, it is necessary to measure the readiness of tourism supporting infrastructure which, will later become the basis for recommendations for developing the Labuan Bajo Flores destination. In this study, we adopt the Tourism and Travel Competitiveness Index (TTCI) or the Tourism Destination Competitiveness Index issued by the World Economic Forum (WEF). With the TTCI study, a mapping of the condition of the tourism sector in the West Manggarai Regency will be obtained in terms of tourism products, infrastructure, government regulations, and supporting sectors. In addition, this data can be the basis for recommendations for determining internal

\begin{tabular}{ll}
\hline How to cite: & Hutagalung, Septian., Moyo Hady Poernomo, Didi Riadi, Rosevan Rudiyanto (2021) Kajian Indeks \\
& Daya Saing Destinasi Pariwisata di Kabupaten Manggarai Barat. Syntax Literate: Jurnal Ilmiah \\
& Indonesia. 6(7). http://dx.doi.org/10.36418/ syntax-literate.v6i7.3659 \\
& 2548-1398 \\
E-ISSN: & Ridwan Institute
\end{tabular}


policies, planning, and developing sustainable tourism destinations in West Manggarai Regency. Data was collected through questionaries and interviews during focus group discussion. The results showed that the tourism industry performance in West Manggarai Regency in total was at a value of 2.1, which means that it is in the stage of refinement. In detail, the value of the four main variables is 2.2 on the product and regulatory variables. 2.1 in infrastructure and support variables.

Keywords: labuanbajo; tourism; TTCI

\section{Pendahuluan}

Daya saing destinasi menjadi sebuah hal yang penting bagi ekonomi. Dengan meningkatkan daya saing destinasi, pemerintah memperoleh manfaat langsung seperti peningkatan Gross Domestic Product (GDP) atau Produk Domestik Bruto (PDB) dari jumlah kedatangan wisatawan mancanegara, serta terbukanya lapangan pekerjaan, terutama di area terpencil yang dapat dihidupkan dari sektor pariwisata (Yakup, 2019). Selain itu, daya saing dapat menjadi tolak ukur untuk memposisikan nilai jual suatu destinasi wisata. Menurut (Dwyer et al., 2003) daya saing destinasi memiliki keterkaitan dengan jumlah kunjungan wisatawan. Pengukuran akan daya saing ini sudah menjadi tema penelitian populer. (Kayar \& Kozak, 2010) meneliti tentang daya saing Turki, (Nazmfar et al., 2019) pada negara Kawasan Timur Tengah, Australia (Dwyer et al., 2003) dan Hongkong (Enright \& Newton, 2004).

Sebelumnya, penelitian daya saing mengukur aspek yang berbeda-beda. Dalam penelitiannya (Nazmfar et al., 2019) menggunakan model analisis Promethee and analisis komparasi data tahun 2015 dan 2017. (Dwyer et al., 2003) menitikberatkan pada penilaian sumber daya alam dan budaya, sumber daya buatan, sumber daya pendukung dan pengelolaan destinasi. Metode Importance Performance Analysis digunakan untuk mengukur daya saing pariwisata Hongkong (Enright \& Newton, 2004). Salah satu mentode terbaru untuk mengukur indekas daya saing, yaitu Tourism and Travel Competitiveness Index (TTCI), yang dikeluarkan oleh World Economic Forum (WEF).

Daya Saing Destinasi Pariwisata. TTCI merupakan salah satu panduan yang digunakan oleh para pemangku kebijakan di hampir setiap negara dalam mengukur tingkat perkembangan suatu destinasi pariwisata. TTCI dikeluarkan oleh organisasi World Economic Forum (WEF) dan diperbarui setiap dua tahun sekali. Indikatorindikator dalam TTCI mengadopsi nilai-nilai sustainable development yang dapat diterapkan dalam suatu destinasi pariwisata (World Economic Forum, 2019).

Didalam Kajian TTCI 2019 yang dikeluarkan oleh WEF ini memiliki beberapa variabel utama, yaitu Potensi Alam, Potensi Budaya dan Bisnis Perjalanan, Infrastruktur, Regulasi, dan Pendukung Pariwisata. Akan tetapi, penelitian yang menggunakan TTCI dilakukan untuk mengukur daya saing pada skala nasional atau negara. Penelitian ini mengukur indeks daya saiing dalam skala yang lebih kecil yaitu kabupaten. 
Dalam kajian di skala kabupaten ini, potensi alam, potensi budaya, dan bisnis perjalanan dimodifikasi menjadi variabel Produk Pariwisata. Hal ini dilatarbelakangi oleh dalam kajian internasional, mayoritas penilaian variabel pertama masih didasari oleh data-data sekunder yang skalanya tidak akan terlalu aplikatif jika diterapkan di skala kabupaten yang lebih kecil dan spesifik. (Kusumawardhani, 2020) mengatakan pada negara berkembang terdapat beberapa indikator yang masih sulit untuk dicapai karena pembangunan di sektor tertentu yang masih dalam proses pembangunan dan membutuhkan waktu cukup lama untuk dapat dinilai setidaknya untuk mencapai nilai minimal indikator TTCI. Variable TTCI yang dijadikan acuan dalam kajian TTCI di Kabupaten Manggarai Barat antara lain:

a. Produk Pariwisata, terdiri dari: Kualitas Produk danKeterlibatan Masyarakat

b. Infrastruktur, terdiri dari: Kualitas dan Akses Bandara, Kualitas Jalan dan Pelabuhan, dan Kualitas Layanan Wisatawan

c. Regulasi, terdiri dari: Prioritas Pariwisata, Keterbukaan, Persaingan Harga dan Keberlanjutan Lingkungan

d. Pendukung Pariwisata, terdiri dari: Lingkungan Usaha, Keamanan, Kualitas SDM, Information and Communiaction Technologies (ICT) dan Kesehatan

Labuan Bajo Flores telah ditetapkan menjadi Destinasi Super Prioritas oleh Presiden Joko Widodo pada tahun 2019 (BPIW, 2020). Di saat yang sama Labuan Bajo juga digagas menjadi Destinasi Wisata Premium karena menjadi gerbang pintu masuk ke Taman Nasional Komodo yang telah ditetapkan sebagai warisan dunia oleh UNESCO pada tahun 1991 (Claudino-Sales, 2019). Selain itu, penetapan Labuan Bajo sebagai Destinasi Premium juga merupakan bentuk persiapan untuk menyambut perhelatan ASEAN Summit dan Pertemuan G-20 yang akan diadakan pada tahun 2023 (BPIW, 2020). Oleh karena itu, penetapan tersebut perlu diiringi dengan pembangunan infrastruktur dan praktik manajemen pariwisata yang berkelanjutan.

Dengan dilakukannya kajian Travel \& Tourism Competitiveness Index (TTCI) maka akan diperoleh pemetaan kondisi sektor pariwisata di Kabupaten Manggarai Barat dalam hal produk pariwisata, infrastruktur, regulasi pemerintah, dan sektor-sektor pendukung. Selain itu, data ini dapat menjadi dasar rekomendasi penetapan kebijakan internal, perencanaan dan pengembangan destinasi pariwisata yang berkelanjutan di Kabupaten Manggarai Barat.

\section{Metode Penelitian}

\section{A. Teknik Pengumpulan Data}

Pengumpulan data dari kajian ini diperoleh dari data primer dan data sekunder. Data primer diperoleh melalui pengisian kuisioner, wawancara dan observasi. Penentuan sampel sumber data dengan purposive sampling. Purposive sampling adalah teknik pengambilan sampel sumber data dengan pertimbangan tertentu (Etikan, 2016). Pertimbangan penulis untuk sampel sumber data adalah harus merupakan stakeholder atau pelaku industri pariwisata. Sehingga, kegiatan pengumpulan datanya dilakukan melalui Focus Group Discussion (FGD) yang 
mengundang Satuan Kerja Perangkat Daerah (SKPD), asosiasi pelaku usaha pariwisata, komunitas kreatif, pemuka agama dan tokoh masyarakat sebagai responden. Sedangkan data sekunder diperoleh dari dokument laporan instansi terkait yang ada di Kabupaten Manggarai Barat.

\section{B. Metode dan Teknik Analisa Data}

Metodologi yang digunakan mengadopsi pendekatan yang digunakan oleh World Economic Forum yaitu Travel and Tourism Competitiveness Index di tahun 2019 dimana beberapa indikator disesuaikan dengan skala pada tingkat kabupaten. Terdapat empat variable utama dalam kajian ini antara lain; 1) Produk (terdiri dari sumber daya alam dan budaya); 2) Infrastruktur (terdiri dari kualitas bandara, jalan \& pelabuhan, fasilitas pelayanan wisata); 3) Regulasi (terdiri dari prioritisasi pariwisata, keterbukaan, daya saing harga, serta keberlanjutan lingkungan); 4) Support (terdiri dari lingkungan usaha bisnis, keselamatan \& keamanan; kesehatan \& higienisitas, SDM, serta kesiapan ICT). Kajian TTCI skala internasional memiliki interval penilaian variabel dan indikator di setiap negara adalah 1 hingga 7. Namun kajian ini, menggunakan skala yang lebih kecil menggunakan interval penilaian 1 hingga 3 dengan keterangan:

1. Nilai 0-1 : Tahap Belum Berkembang

2. Nilai 1-2 : Tahap Berkembang

3. Nilai 2-3 : Tahap Penyempurnaan

\section{Hasil dan Pembahasan}

Penelitian dilakukan pada bulan desember 2020. Pengumpulan data dilakukan melalui FGD dengan mengundang dinas terkait, perwakilan pelaku usaha pariwisata, tokoh agama dan tokoh adat, Adapun daftar undangan yang hadir adalah sebagai berikut:

1. Dinas Pariwisata

2. Dinas Perhubungan

3. Dinas Kesehatan

4. Disnakertrans

5. Dinas PUPR

6. Dinas Pendidikan dan Kebudayaan

7. Badan Keuangan Daerah

8. Dinas Lingkungan Hidup

9. Dinas Pertanahan

10. Dinas Koperasi dan Perdagangan

11. Dinas Kominfo

12. Dinas Perikanan dan Kelautan

13. Dinas Penanaman Modal dan PTSP

14. Bapelitbangda

15. Kepala Kepolisian Resor
16. Badan Penanaman Modal Daerah

17. Badan Keuangan Daerah

18. Pengelola Bandar Udara

19. PHRI

20. ASITA

21. HPI

22. Perhimpunan Ranger Taman Nasional

23. PT. Telkom

24. Pemuka Adat

25. Perwakilan Komunitas Kreatif

26. Pemuka Agama, Pemuka Adat dan Tokoh Masyarakat 
Hasil pengisian kuisioner yang telah diisi oleh responden secara spesifik sesuai dengan variabel-variabel yang digunakan dalam TTCI.

\section{Produk Pariwisata}

Produk wisata merupakan keseluruhan fasilitas atau pelayanan berbentuk nyata atau tidak nyata yang diperoleh dan dirasakan atau dinikmati oleh wisatawan agar suatu kesatuan rangkaian perjalanan dapat memberikan pengalaman yang baik bagi wisatawan semenjak meninggalkan tempat tinggalnya sampai ke daerah tujuan wisata hingga kembali ketempat asalnya (Octaviany, 2016). Nilai Indikator Produk Pariwisata untuk Kabupaten Manggarai Barat adalah 2.2, di mana variabel pendukungnya terdiri dari kualitas produk pariwisata (1.9) dan pelibatan masyarakat (2.2). Terkait dengan perolehan nilai untuk kualitas produk sedikit di atas nilai ratarata (1.9) menandakan bahwa Kabupaten Manggarai Barat masih perlu pembenahan untuk peningkatan kualitas produk pariwisatanya jika dibandingkan dengan perolehan nilai untuk potensi atau keistimewaan daya tarik wisata alam maupun budaya dengan nilai 2.7, di mana salah satunya yaitu Taman Nasional Komodo telah ditetapkan sebagai Warisan Dunia oleh UNESCO pada tahun 1991 dan juga sebagai Cagar Biosfer Nasional tahun 1977 (Hidranto, 2020).

Kabupaten Manggarai Barat dengan daya tarik utamanya Taman Nasional Komodo telah ditetapkan sebagai salah satu Destinasi Pariwisata Super Prioritas dan diharapkan dapat menjadi salah satu ikon pariwisata di Indonesia. Untuk memperkuat keistimewaan daya tarik wisatanya maka dibutuhkan penyusunan narasi seperti mengembangkan konsep storynomic tourism yaitu pendekatan komunikasi pariwisata yang mengedepankan narasi, konten kreatif dan kekuatan sejarah dan budaya (McKee \& Gerace, 2018). Penyusunan narasi daya tarik wisata ini bertujuan untuk memperkaya informasi dan memperdalam deskripsi tentang kekayaan alam budaya Kabupaten Manggarai Barat dalam kemasan menarik, berkualitas, dan siap digunakan untuk menunjang promosi dan pemasaran destinasi yang memperoleh nilai 1.8 .

Selama tahun 2020, Kabupaten Manggarai Barat terus berupaya untuk menciptakan diversifikasi produk wisata dengan melibatkan peran aktif masyarakat (2.3) berupa pelatihan dan pengembangan keterampilan di bidang pariwisata dan industri kreatif (2.3). Salah satunya adalah dengan pengembangan kawasan Kampung Air yang akan dijadikan sebagai pilot project untuk pengembangan daya tarik wisata berbasiskan masyarakat. Pengembangan pariwisata berbasis masyarakat sendiri menurut Hausler dalam (Nurhidayati, 2007) merupakan suatu pendekatan pembangunan pariwisata yang menekankan pada masyarakat lokal (baik yang terlibat langsung dalam industri pariwisata maupun tidak) dalam bentuk memberikan akses dalam manajemen dan pembangunan pariwista yang berujung pada pemberdayaan politis melalui kehidupan yang lebih demokratis, termasuk dalam pembagian keuntungan dari kegiatan pariwisata yang lebih adil bagi masyarakat lokal. Kawasan Kampung Air sendiri merupakan pemukiman dengan 
budaya masyarakat pesisir kental dan dihuni oleh masyarakat keturunan Bajo, Bugis dan Bima.

\section{Infrastruktur}

Menurut peraturan (Peraturan Presiden RI, 2015) infrastruktur adalah fasilitas teknis, fisik, sistem, perangkat keras, dan lunak yang diperlukan untuk melakukan pelayanan kepada masyarakat dan mendukung jaringan struktur agar pertumbuhan ekonomi dan sosial masyarakat dapat berjalan dengan baik. Secara keseluruhan, nilai Infrastruktur berada pada nilai 1.85. Ini terdiri dari sub-indikator Kualitas dan Akses Bandara, Kabupaten Manggarai Barat memperoleh nilai 2.8 dari 3 sebagai angka tertinggi. Perolehan angka ini tergolong cukup baik dikarenakan Kabupaten Manggarai Barat telah didukung oleh hadirnya infrastruktur Bandar Udara kelas 2 yang pengelolaannya masih di bawah Kementerian Perhubungan melalui UPT Ditjen Hubud bekerja sama dengan PT. Cardig Aero Services. Bandar Udara Komodo sejauh ini baru melayani penerbangan domestik dengan jumlah tujuh maskapai yaitu Garuda Indonesia, City Link, Batik Air, Indonesia Air Asia, NAM Air, Transnusa dan Wings Air. Bandara Komodo saat ini melayani penerbangan dengan rute dari dan ke Jakarta (Soekarno-Hatta International Airport), Surabaya, Denpasar, Makassar, Lombok, Kupang, Tambolaka, Waingapu, Ruteng, Bajawa, Ende, Maumere, Larantuka, dan Alor (Direktorat Jenderal Perhubungan Udara, 2011). Pesawat yang diakomodasi seperti Airbus 320, Boeing dan ATR 72. Panjang lintasan 2.250 X $45 \mathrm{~m}$ dan akan bertambah menjadi 2.450 X $45 \mathrm{~m}$ (Budhiman, 2018).

Dari Sub-indikator Kualitas Jalan dan Pelabuhan, Kabupaten Manggarai Barat juga memperoleh nilai 2.5 dari 3 sebagai angka tertinggi, hampir seluruh responden menyatakan bahwa kualitas jalan di Kabupaten Manggarai Barat masih belum semuanya baik dan sebagian menyatakan karena saat ini tengah dilakukan perbaikan akses jalan utama di Kota Labuan Bajo. Dari segi pelabuhan, kualitas pelabuhan di Kabupaten Manggarai Barat memperoleh nilai sebesar 2.5 dengan jumlah responden lebih dari 50\% menganggap bahwa kualitas pelabuhan di Kabupaten Manggarai Barat sudah tergolong baik. Untuk pelabuhan, ASDP Marina merupakan proyek pembangunan Kawasan Komersial Labuan Bajo melalui kerja sama antara BPT ASDP Indonesia Ferry (Persero), PT. Pembangunan Perumahan (Persero) dan PT. Patra Jasa. Pembangunan meliputi Pelabuhan Marina, peningkatan fasilitas dermaga penyeberangan, hotel dan area komersial.

Untuk sisi Kualitas Pelayanan Wisatawan memperoleh angka 2.3 di mana beberapa fasilitas pelayanan wisata seperti Tourist Information Center (TIC) saat ini tengah dibangun di kawasan Puncak Waringin. Beberapa responden menyebutkan bahwa perlu juga untuk reaktivasi TIC milik Dinas Pariwisata untuk lebih mengoptimalkan pelayanan informasi terhadap wisatawan. Namun untuk kualitas pelayanan fasilitas menginap dan rumah makan di beberapa tempat dianggap masih kurang terkait dengan kualitas SDM. 


\section{Regulasi}

Pariwisata telah semakin disadari sebagai pemicu pertumbuhan ekonomi dan peluang perluasan lapangan kerja di berbagai daerah. Meskipun demikian, bahwa keberhasilan pengembangan sektor pariwisata lebih banyak ditentukan oleh peran kebijakan pemerintah yang ikut serta secara aktif membangun regulasi untuk pengembangan kepariwisataan (Afandi et al., 2017). Dari sisi regulasi Kabupaten Manggarai Barat memperoleh nilai 2.2 di mana sektor pariwisata merupakan sektor yang prioritas di dalam pembangunan daerahnya. Dalam hal keterbukaan nilai yang diperoleh Kabupaten Manggarai Barat adalah 1.9 di mana kebijakan Pemerintah Pusat seperti mengenai bebas visa selama 30 hari bagi wisatawan mancanegara cukup memberikan dampak yang positif bagi jumlah kunjungan dan lama tinggal wisatawan ke Kabupaten Manggarai Barat. Penilaian terhadap indikator persaingan harga di Kabupaten Manggarai Barat tergolong baik dengan nilai 2.1 meskipun harga untuk fasilitas wisata seperti hotel dan restoran termasuk mahal. Hal ini juga menjadi perhatian dari Dinas Pariwisata dan Kebudayaan untuk segera melakukan evaluasi terhadap persaingan harga di Manggarai Barat khususnya di Kota Labuan Bajo. Terkait aspek keberlanjutan lingkungan, nilai yang didapatkan di dalam pengukuran TTCI ini adalah 2.2 di mana Kabupaten Manggarai Barat telah memiliki kebijakan terkait lingkungan dalam bentuk Perda, SK Bupati dan lain sebagainya.

\section{Pendukung Pariwisata}

Indikator Pendukung Pariwisata secara total berada pada nilai 2.1 di Kabupaten Manggarai Barat yang terdiri dari beberapa sub-indikator seperti lingkungan usaha (2) yang menggambarkan bahwa perlindungan usaha dan pelayanan hukum terkait usaha sudah berjalan baik di kabupaten ini. Demikian juga dengan keamanan dan keselamatan (2.2) di mana angka kriminalitas dan gangguan terorisme tidak begitu tinggi sehingga menjadikan Kabupaten Manggarai Barat sebagai kawasan yang cukup aman bagi pengembangan usaha di industri pariwisata.

Terkait kualitas SDM (2.1) di Kabupaten Manggarai Barat masih perlu peningkatan kualitas melalui berbagai pelatihan dan penguatan kapasitas jika dilihat bahwa di Labuan Bajo akan terus berkembang sebagai sebuah destinasi pariwisata akan segera menyelenggarakan berbagai perhelatan kelas dunia. Ini semua harus diiringi dengan peningkatan kualitas Sumber Daya Manusia.

Keberadaan Internet/Web kini merupakan wahana yang potensial untuk mempromosikan pariwisata (Suleman, 2013). Pada sub indikator ICT (2) yang terdiri dari pemanfaatan internet dalam usaha (2.2), suplai listrik (2.1), dan pemanfaatan teknologi dalam usaha (2.4) Penggunaan teknologi berbasiskan internet sudah cukup bagus (2.0). Pelaku usaha di Labuan Bajo sudah merasakan di bidang usaha seperti pemanfaatan media sosial untuk promosi usaha, penggunaan gawai EDC dalam transaksi non tunai dan pengembangan aplikasi berbasiskan internet. Indikator penunjang pariwisata lainnya adalah layanan Kesehatan (2.1) di mana Kabupaten Manggarai Barat memiliki fasilitas kesehatan sebanyak 109 unit yang terdiri dari 2 Rumah Sakit Umum, 9 unit Puskesmas rawat inap, 12 unit 
Puskesmas non rawat inap, 28 unit Puskesmas keliling, 36 unit Puskesmas pembantu dan 22 unit Apotek (BPS Kabupaten Manggarai Barat 2019).

Secara keseluruhan performa industri pariwisata Kabupaten Manggarai Barat berada pada nilai 2.1 seperti pada gambar 1 . Nilai tersebut diperoleh dari gabungan nilai tiap variabel yang digunakan dalam Travel and Tourism Competitiveness Index (TTCI) seperti pada gambar 2. Hal ini seturut dengan penelitian indeks daya saing di Turki. (Kayar \& Kozak, 2010) mengatakan destinasi dengan nilai tinggi pada variabel infrastruktur, regulasi, sumberdaya alam dan budaya merupakan destinasi yang memiliki kinerja lebih baik pada daya saing pariwisata. Lebih lanjut dalam penelitian yang sama Kayar dan Kozak mengatakan destinasi dengan nilai tinggi ini juga akan memiliki nilai jual yang lebih besar pada pasar internasional.

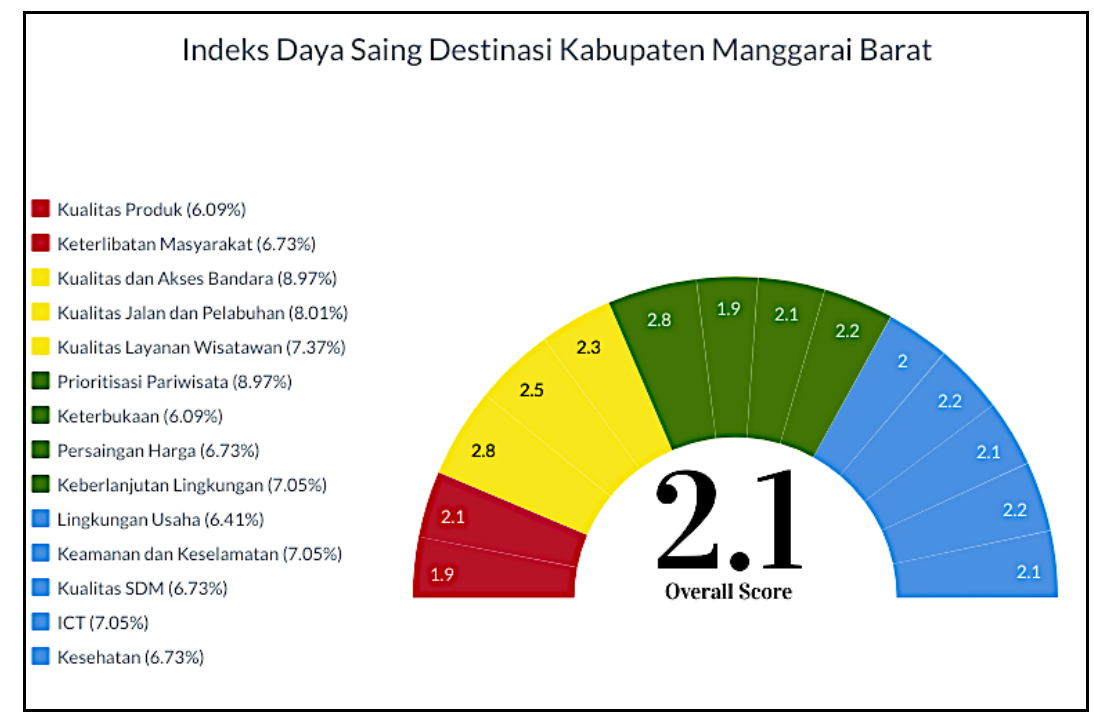

Gambar 1

Indeks Daya Saing Pariwisata Kabupaten Manggarai Barat 2020

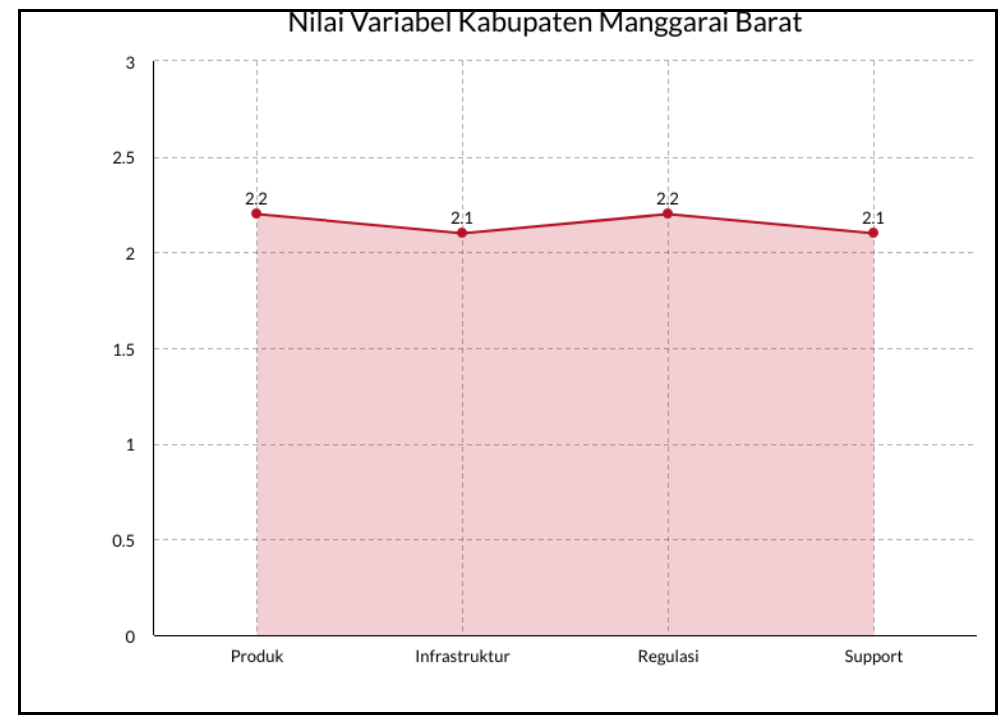

Gambar 2

Nilai Variabel Kabupaten Manggarai Barat 2020 


\section{Kesimpulan}

Performa industri pariwisata Kabupaten Manggarai Barat berada pada secara total berada pada nilai nilai 2.1 yang berarti berada pada tahap penyempurnaan. Nilai variabel pada masing-masing empat variabel utama berada pada nilai 2.2 pada variabel produk dan regulasi kemudian nilai infrastruktur dan support pada 2.1.

Indeks Daya Saing Destinasi dapat digunakan sebagai cerminan atau alat ukur keberhasilan pembangunan sebuah destinasi secara luas. Indeks ini juga dapat digunakan sebagai alat ukur tingkat kesejahteraan masyarakat dan merupakan potret pembangunan sebuah daerah.

Indeks Daya Saing Destinasi atau Travel and Tourism Competitiveness Index (TTCI) sangat penting dilakukan karena pengukuran TTCI bertujuan menginformasikan struktur komunikasi multi-stakeholder yang dapat meningkatkan sinergitas dalam pembangunan pariwisata di wilayah kabupaten dan pusat seperti Badan Pelaksana Otorita Labuan Bajo Flores (BOPLBF), dengan menciptakan potensi sumber daya alam dan budaya, serta sumber daya manusianya yang dapat memberikan manfaat menyeluruh dan berkelanjutan di sektor pariwisata. 


\section{BIBLIOGRAFI}

Afandi, A., Sunarti, S., \& Hakim, L. (2017). Peran Pemerintah Daerah Dalam Pengembangan Destinasi Wisata Bahari Pulau Gili Noko Kabupaten Gresik (Studi Pada Dinas Kebudayaan, Pariwisata, Pemuda dan Olahraga Kabupaten Gresik). Jurnal Administrasi Bisnis S1 Universitas Brawijaya, 49(1). Google Scholar

BPIW, L. I. (2020). BPIW Susun ITMP Labuan Bajo Untuk Mendukung Peningkatan Jumlah Wisatawan.

Budhiman, I. (2018). Ini Rencana Pengembangan Bandara Komodo di Labuan Bajo.

Claudino-Sales, V. (2019). Komodo National Park, Indonesia. In Coastal Research Library (Vol. 28). https://doi.org/10.1007/978-94-024-1528-5_80 Google Scholar

Direktorat Jenderal Perhubungan Udara. (n.d.). Data Bandar Udara. 2019.

Dwyer, L., Livaic, Z., \& Mellor, R. (2003). Competitiveness of Australia as a Tourist Destination. Journal of Hospitality and Tourism Management, 10(1). Google Scholar

Enright, M. J., \& Newton, J. (2004). Tourism destination competitiveness: A quantitative approach. Tourism Management, 25(6). https://doi.org/10.1016/j.tourman.2004.06.008 Google Scholar

Etikan, I. (2016). Comparison of Convenience Sampling and Purposive Sampling. American Journal of Theoretical and Applied Statistics, 5(1), 1. https://doi.org/10.11648/j.ajtas.20160501.11

Hidranto, F. (2020). Pengakuan Unesco untuk Tiga Cagar Biosfer Indonesia.

Kayar, Ç. H., \& Kozak, N. (2010). Measuring destination competitiveness: an application of the travel and tourism competitiveness index (2007). Journal of Hospitality Marketing \& Management, 19(3), 203-216. Google Scholar

Kusumawardhani, Y. (2020). Kajian 14 Pillar Pada Travel and Tourism Competitiveness Index (TTCI) Sebagai Indikator Daya Saing Pariwisata Suatu Negara. Tourism Scientific Journal, 6(1). https://doi.org/10.32659/tsj.v6i1.129 Google Scholar

McKee, R., \& Gerace, T. (2018). Storynomics, Story-Driven Marketing in the PostAdvertising World. In Twelve, New York-Boston (Vol. 53, Issue 9). Google Scholar

Nazmfar, H., Eshghei, A., Alavi, S., \& Pourmoradian, S. (2019). Analysis of travel and tourism competitiveness index in middle-east countries. Asia Pacific Journal of Tourism Research, 24(6). https://doi.org/10.1080/10941665.2019.1590428 Google Scholar 
Septian Hutagalung, Moyo Hady Poernomo, Dodi Riadi, Roseven Rudiyanto

Nurhidayati, S. E. (2007). Community Based Tourism (CBT) sebagai Pendekatan Pembangunan Pariwisata Berkelanjutan. Jurnal Masyarakat, Kebudayaan, Dan Politik Universitas Airlangga, Th XX 3(3). Google Scholar

Octaviany, V. (2016). Pengaruh Kualitas Produk Pariwisata Terhadap Keputusan Berkunjung Di Bale Seni Barli-Kota Bary Parahyangan. Tourism Scientific Journal, 1(2). https://doi.org/10.32659/tsj.v1i2.11 Google Scholar

Peraturan Presiden RI, S. (2015). Peraturan Presiden Republik Indonesia Nomor 38 Tahun 2015 Tentang Kerjasama Pemerintah Dengan Badan Usaha Dalam Penyediaan Infrastruktur. Lembaran Negara, 151. Google Scholar

Suleman. (2013). Pemanfaatan Ict (Information and Communication Technology) Dalam Promosi Pariwisata Di Indonesia. Bianglala Informatika, 1(1). Google Scholar

World Economic Forum. (2019). The Travel \& Tourism Competitiveness Report 2019. In World Economic Forum (Ed.), World Economic Forum (Vol. 44, Issue October). Google Scholar

Yakup, A. P. (2019). Pengaruh Sektor Pariwisata Terhadap Pertumbuhan Ekonomi di Indonesia. In Universitas Airlangga Surabaya. Google Scholar

\section{Copyright holder:}

Septian Hutagalung, Moyo Hady Poernomo, Dodi Riadi, Roseven Rudiyanto (2021)

First publication right:

Syntax Literate: Jurnal Ilmiah Indonesia

This article is licensed under: 